\title{
Experimental Research on low temperature crack resistance of steel fiber asphalt concrete
}

\author{
Junjun Pei 1, a , Qilong Guo ${ }^{1, b}$ Jianli Pang 1,c \\ ${ }^{1}$ School of civil engineering, Northwest University for Nationalities \\ lanzhou and 730124, P. R. china \\ apjj061185@126.com, bguoqilong8@126.com, c171275366@qq.com
}

\begin{abstract}
Keywords: Steel fiber;asphalt mixture; low temperature crack resistance
Abstract. How to improve the low temperature performance of asphalt mixture is crucial because low temperature cracking is one of the most common diseases of asphalt pavement. The steel fiber is a effective method in the ordinary asphalt mixture. The effect of steel fiber on the low temperature crack resistance of asphalt concrete is analyzed in cases of different temperatures and contents of steel fiber through the bending test of small beam. It is shown that the flexural tensile strength and the failure strain of the asphalt concrete decreased linearly with the decrease of temperature. Added steel fiber content immensely changed the size of flexural tensile strength(maximum rose to $31.8 \%$ ). With the increasing of steel fiber content, the flexural tensile strength increases the amplitude showd o rising trend. It is suggested that improved flexural tensile strength and anti-deformability of asphalt concrete after adding steel fiber effectively increase anti-crackingability under low temperature.
\end{abstract}

\section{Introduction}

Low temperature cracking of asphalt pavement is one of the main forms of road damage. Which is very common in many countries and regions such as North America, Canada, Russia, and North China[1]. The harm is that from the cracks lead the basic level and even the roadbed to soften as for water continuous leak into them through these cracks, which decreases the road structure carrying capacity[2]. Aiming at the problem of low temperature shrinkage cracking of asphalt pavement, the low temperature cracking resistance of steel fiber asphalt mixture was investigated and studied in the domestic and international. In 1968, the first time in Germany put forward the method of short fiber reinforced modification. The results show that the stability of the asphalt is improved by the addition of fiber[3], Subsequently, the United States of America's Bonifber, FiberPave[4], and Germany's DolanitAs, Arbocel[5] enhance the performance of fiber reinforced asphalt pavement research climax. In 2002, experimental study and theoretical analysis on asphalt concrete mixed with polyethylene fiber was carried out by Bradley[6]. The results show that the low temperature performance of asphalt concrete has been greatly improved. From 1992 to December 2002, Hebei Province, the steel fiber asphalt concrete surface layer of a more in-depth study, has achieved the desired results Bradley[7]. In 1998, the Luqiao Xinjiang Corporation joined the steel fiber in the asphalt concrete, and conducted the research on the indoor research and the test shop. The results show that the steel fiber can effectively increase the pavement performance of asphalt pavement. Therefore, on the basis of existing research results, this paper through bending test of small beam measured bending temperature crack resistance flexural tensile strength $R_{B}$, flexural tensile strain $\varepsilon_{B}$ and stiffness modulus $S_{B}$ to evaluate the steel fiber asphalt mixture.

\section{Experiment materials}

Asphalt in this study is the heavy traffic AH-70 petroleum asphalt, its technical indicators are shown in Table 1. Physical properties of steel fiber are shown in Table 2. Mixture gradation is AC-16C, Asphalt aggregate ratio is $6 \%$, the gradation composition of mixtures are shown in table 3 . 
Table 1 Technical indexes of the asphalt

\begin{tabular}{ccc}
\hline Items & Measured value & Limited value \\
\hline Penetration $\left(25^{\circ} \mathrm{C}, 100 \mathrm{~g}, 5 \mathrm{~s}\right)(0.01 \mathrm{~mm})$ & 67 & $60 \sim 80$ \\
Softening point $\left({ }^{\circ} \mathrm{C}\right)$ & 47.1 & $\geqslant 42$ \\
Ductility $\left(15^{\circ} \mathrm{C}, \mathrm{cm}\right)$ & 106 & $\geqslant 100$ \\
Open flashing point $\left({ }^{\circ} \mathrm{C}\right)$ & 332 & $\geqslant 245$ \\
Density $\left(15^{\circ} \mathrm{C}, \mathrm{g} \cdot \mathrm{cm}^{-3}\right)$ & 1.024 & Measured \\
\hline
\end{tabular}

Table 2 physical properties of steel fiber

\begin{tabular}{|c|c|c|c|c|c|c|c|c|c|c|c|}
\hline tensile strength & & \multicolumn{3}{|c|}{$\begin{array}{c}\text { Ratio of length to } \\
\text { diameter }\end{array}$} & \multicolumn{3}{|c|}{ length (mm) } & \multicolumn{4}{|c|}{$\begin{array}{l}\text { Equivalent diameter } \\
(\mathrm{mm})\end{array}$} \\
\hline$\geqslant 380$ & & \multicolumn{3}{|c|}{108} & \multicolumn{3}{|c|}{12.71} & \multicolumn{4}{|c|}{0.12} \\
\hline Sieve size $(\mathrm{mm})$ & 19 & 16 & 13.2 & 9.5 & 4.75 & 2.36 & 1.18 & 0.6 & 0.3 & 0.15 & 0.075 \\
\hline $\begin{array}{c}\text { Mesh passing } \\
(\%)\end{array}$ & 100 & 96 & 85 & 70 & 47 & 31 & 26 & 19 & 12 & 8 & 6 \\
\hline
\end{tabular}

\section{Test methods}

Test method and sample preparation are available in the Standard Test Methods of Bitumen and Bituminous Mixtures for Highway Engineering(PRC Industry Standard 2011). The test equipment used Changsha Yaxing trabecular bending test machine. The test temperature is $-40{ }^{\circ} \mathrm{C},-30{ }^{\circ} \mathrm{C},-20$ ${ }^{\circ} \mathrm{C},-10^{\circ} \mathrm{C}, 0^{\circ} \mathrm{C}$ and $10^{\circ} \mathrm{C}$. The height, width and length of the small beam test piece are $35 \mathrm{~mm} \pm 2 \mathrm{~mm}$ 、 $30 \mathrm{~mm} \pm 2 \mathrm{~mm} 、 250 \mathrm{~mm} \pm 2 \mathrm{~mm}$, and the span is $200 \mathrm{~mm}$. The loading rate is $50 \mathrm{~mm} / \mathrm{min}$. According to the maximum load $P_{\mathrm{B}}$ and span deflection $d$. Calculating the flexural failure of the tensile strength $R_{\mathrm{B}}=\frac{3 L P_{\mathrm{B}}}{2 b h^{2}}$, flexural tensile strain $\varepsilon_{\mathrm{B}}=\frac{6 h d}{L^{2}}$ and stiffness modulus of trabecular $S_{\mathrm{B}}=\frac{R_{\mathrm{B}}}{\varepsilon_{\mathrm{B}}}$

\section{Experiment results and discussion}

In this experiment, the test specimens were tested under different temperature by controlling the temperature condition. Experimental study and comparative analysis of AC-16C asphalt concrete and three kinds of asphalt concrete with different steel fiber content were carried out. Through experiments, the bending tensile strength, failure strain and bending stiffness modulus of specimens at different temperatures were obtained.

Effect of temperature on flexural tensile strength

Flexural tensile strength varying with temperatures from $-40^{\circ} \mathrm{C}$ to $10^{\circ} \mathrm{C}$ in cases of different steel fiber content as show in figure 1. seen from the figure, Steel fiber asphalt concrete will exhibit different mechanical properties at different temperatures. With the decrease of temperature, the flexural tensile strength of asphalt concrete is almost linearly decreased. The size of the flexural strength was changed because of the addition of steel fiber. But the trend that flexural tensile strength decreased with temperature did not change. 


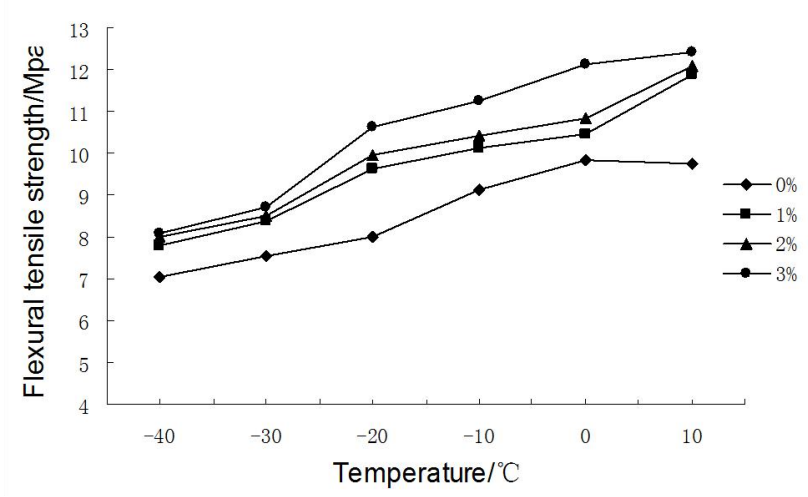

Figure 1. Curves of flexural tensile strength vs. temperature

Effect of steel fiber content on flexural tensile strength

Flexural tensile strength varying with steel fiber content from $0 \%$ to $3 \%$ in cases of different temperatures as show in figure 2. seen from the figure, Compared to ordinary asphalt concrete, Steel fiber asphalt concrete flexural strength were improved. With the steel fiber content increased, the flexural tensile strength showed a rising trend, When the test temperature is $-20^{\circ} \mathrm{C}$, the asphalt concrete that steel fiber content $(3 \%$ ) can make flexural strength increased by $31.8 \%$. Compared with ordinary asphalt concrete, The ultimate flexural tensile strength of steel fiber reinforced asphalt concrete is improved due to the reinforcement of steel fiber, and the low temperature cracking resistance is better, and with the increase of steel fiber content in a certain range, the flexural tensile strength increased.

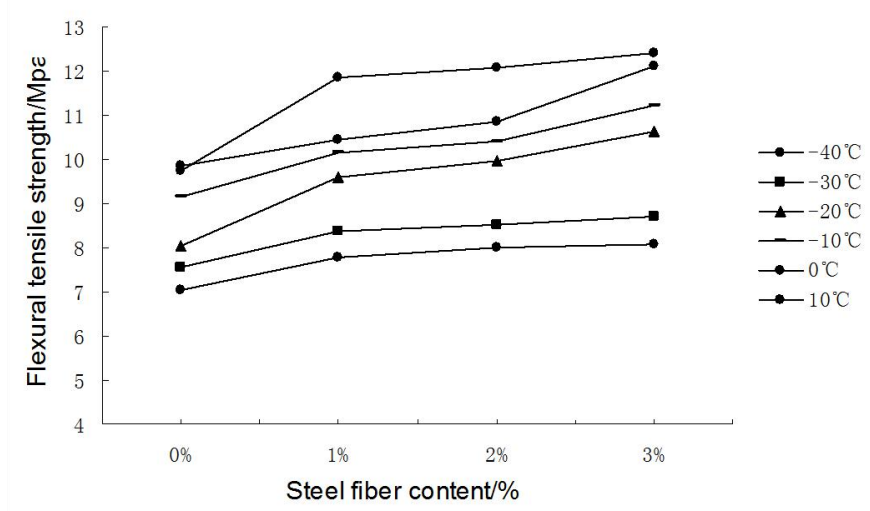

Figure 2. Curves of flexural tensile strength vs. steel fiber content

Effect of temperature on flexural tensile strair

Flexural tensile strair varying with temperatures from $-40^{\circ} \mathrm{C}$ to $10^{\circ} \mathrm{C}$ in cases of different steel fiber content as show in figure 3. seen from the figure, With the decrease of temperature, the failure strain of asphalt concrete with different mixing amount decreased with the decrease of temperature, the asphalt concrete with different steel fiber content has no obvious change when the temperature is below $0^{\circ} \mathrm{C}$, Therefore, the temperature area below $0{ }^{\circ} \mathrm{C}$ can be considered as a region of complete elastic behavior of asphalt concrete. 


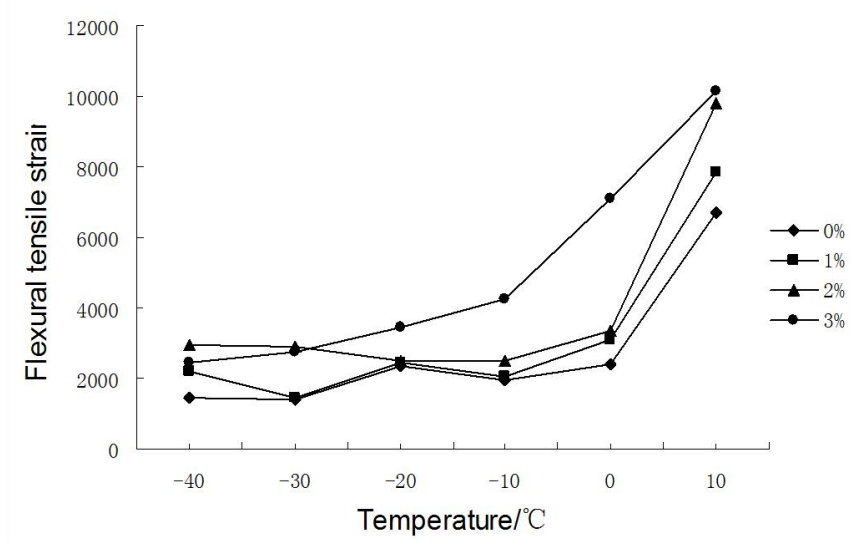

Figure 3. Curves of flexural tensile strair vs. temperature

Effect of steel fiber content on flexural tensile strair

Flexural tensile strair varying with steel fiber content from $0 \%$ to $3 \%$ in cases of different temperatures as show in figure 4 . seen from the figure, The failure strain of asphalt concrete added with steel fiber has been increased. and the failure strain of concrete with a content of $2 \%$ is the largest. At various temperatures in the range $-20^{\circ} \mathrm{C}$ to $10^{\circ} \mathrm{C}$, the failure strain increases with the increase of the fiber content. The steel fiber content with maximum failure strain of concrete is $3 \%$. The steel fiber content is higher, the number of crossing steel fiber interface crack is more, steel fiber consumption in the process of pulling unwound stick more energy. At the same time, Micro cracks formed due to the bonding slip between steel fiber and matrix asphalt in the role of the corresponding stress because of the bridge effect of steel fiber, When the macroscopic crack growth, the crack is not broken, and the strain hardening behavior is shown, so that the damage of the asphalt concrete matrix has a greater ability to resist deformation.

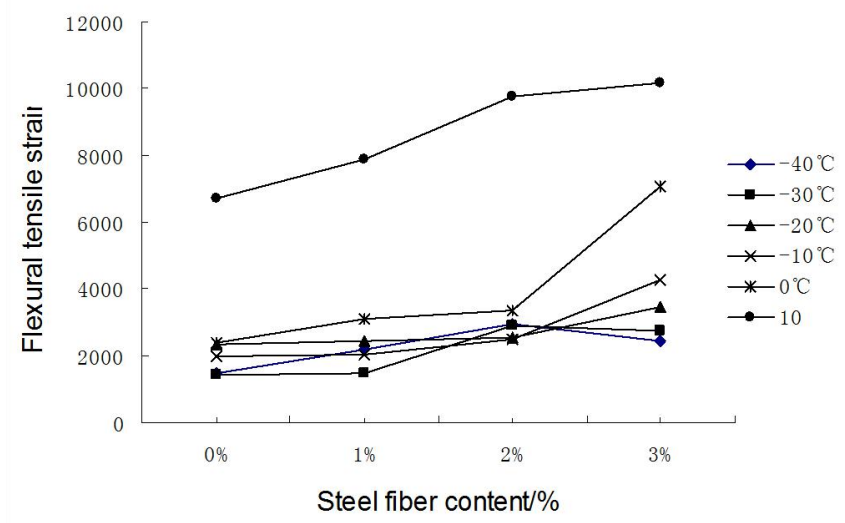

Figure 4. Curves of flexural tensile strair vs. steel fiber content

\section{Effect of steel fiber content on stiffness modulus}

Stiffness modulus varying with steel fiber content from $0 \%$ to $3 \%$ in cases of different temperatures as show in figure 5. Stiffness modulus is one of the evaluation indexes of low temperature performance of asphalt concrete, which can be used to evaluate the cracking resistance of asphalt concrete at low temperature. seen from the figure, stiffness modulus increases with the decrease of temperature. The addition of steel fiber changes the stiffness modulus, which influences the low temperature damage characteristics. When the temperature is in the range of $-20^{\circ} \mathrm{C}$ to $10^{\circ} \mathrm{C}$, the Steel fiber content at the lowest stiffness modulus is $3 \%$, so the low temperature performance is relatively better. Overall, Asphalt concrete stiffness modulus decreased by elastic brittle to flexible ductility failure at any temperature from $-40^{\circ} \mathrm{C}$ to $10^{\circ} \mathrm{C}$ with the increase of dosage of steel fibre. 


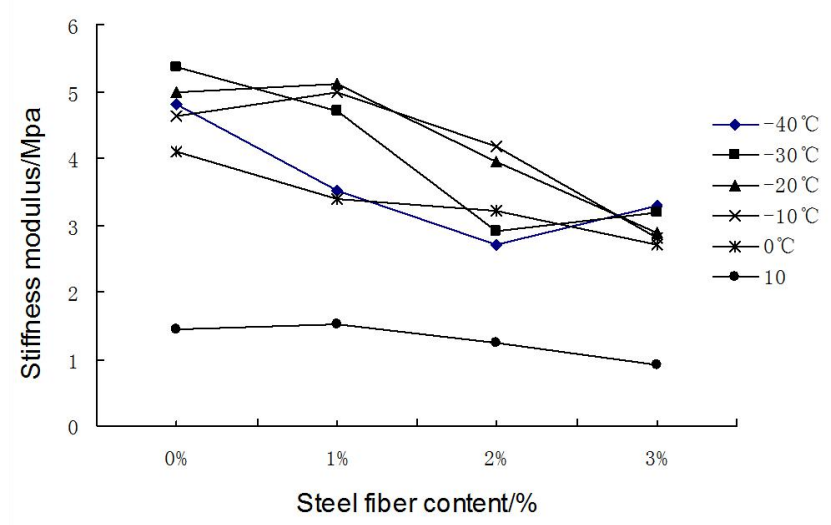

Figure 5. Curves of stiffness modulus vs. steel fiber content

\section{Conclusions}

Based on the analysis of low temperature bending test results of ordinary asphalt concrete and steel fiber asphalt concrete beams, the following conclusions can be drawed:

1. In the temperature range of $-40^{\circ} \mathrm{C}$ to $+10^{\circ} \mathrm{C}$, with the temperature decreasing, the flexural tensile strength of asphalt concrete is nearly linearly decreased, the addition of steel fibers steel did not change the inherent law of asphalt concrete flexural strength decreases with temperature changed the size of bending strength. The flexural tensile strength of asphalt concrete can be improved with addition of steel fiber, and the flexural tensile strength increases with the increases of steel fiber content. the asphalt concrete that steel fiber content is $3 \%$ can make flexural strength increased by $31.8 \%$.

2. In the temperature range of $-40^{\circ} \mathrm{C}$ to $+10^{\circ} \mathrm{C}$, the failure strain of asphalt concrete with different content of steel fiber decreased with the decrease of temperature, The anti-deformaability ability of asphalt concrete is improved gradually with the increase of steel fiber content at any temperature.

3. the stiffness modulus of asphalt concrete and steel fiber asphalt concrete increased with the decrease of temperature in the temperature range of $-40^{\circ} \mathrm{Cto}+10^{\circ} \mathrm{C}$. But the addition of steel fiber affected the stiffness modulus of the size not affected the low temperature damage characteristics. At certain temperature, the stiffness modulus of asphalt concrete is decreased with the increase of steel fiber content, which is changed from elastic brittle failure to flexible ductile failure.

\section{Acknowledgements}

This work was financially supported by the Fundamental Research Funds for the Central Universities (31920160087)

\section{References}

[] Zeng R.B., Zhang Y.H,.Wu G.X. Study on Impaction of Modified Asphalt and Polyester Fiber for Low Temperature Property of Asphlt Mixture[A]. Chongqin: Journal of Chongqing Jiaotong University, 2010,29(5):722-723

[2] Hao P.W., Zhang D.L.and Hu X.N.. The Evaluation Index of Low Temperature Crack Resistance of Asphalt Mixture[J].Xi'an: Xi'an Highway Traffic University Journal, 2000, 20(3):1-5

[3]He D.Y..Study on the performance of fiber reinforced asphalt concrete[D] Chongqing: Chongqing Jiaotong College, road and railway engineering, 2005

[4] Shiou-SanKuo,Jamshid M Armaghani,Dave Scherling."Accelerated Pavement Performavce Testing of Ultra-Thin Fiber Reinforced Concrete Overlay, Recycled Concrete Aggregate, and Patching Materials"'[J].2002,(6):36-39

[5] Jeb S Ting,M.ASCE;Rosa L.Santoni,M.ASCE; and Steve L.Webster,M.ASCE,Full-Scale Field Test of Discrete Fiber-Reinforcde[S].Journal of Transportation Engineering,2002,(9):15-19 
[6] Bradley. Serji N.Airkhanian Utilizantlon of waste fibers in stone matrix asphalt mixtures.Resources, Conservation and Recycling,2004,42(3): 265-274.

[7] Zhu J.M..Study on Application of steel fiber asphalt concrete surface layer[D]. Traffic standardization, 2004, (6): 78-80 